\title{
Measuring Slice-of-Life Versus Slice-of-Death Advertising Appeals: An Abstract
}

\author{
Anshu Saxena Arora, Amit Arora, and Shalonda K. Bradford
}

\begin{abstract}
The article focuses on slice of life (SOL) and slice of death (SOD), as two types of semantic differential advertising appeals. We developed and validated a scale for measuring slice-of-life and slice-of-death (SOL\&D) advertising appeals through our conceptualization of SOL\&D advertising comprising of three factors: advertising complexity, advertising relevance, and advertising valence. SOL\&D appeals use these three factors to evoke both positive and negative emotions in advertising, which in turn contribute to attitudes toward the ad and brand. Utilizing the theory of emotional information management (EIM), which draws on the emotional intelligence (EI) literature, we generated three indicators of advertising complexity, three indicators of advertising relevance, and four indicators of advertising valence. The authors make conceptual, measurement, and managerial contributions to the research dealing with slice-of-life versus slice-of-death advertising appeals. The research extends message framing and emotional advertising literature by utilizing emotional informational management framework for measuring and evaluating SOL\&D advertising appeals. Practitioners will consider our findings relevant, while future researchers may view our study as a springboard into areas of SOL\&D advertising and branding, advertising polysemy, consumer-based brand equity, and cultural differences in interpretation of SOL\&D advertising attitudes and purchase intentions.
\end{abstract}

\section{References}

Available upon request.

A.S. Arora $(\bowtie) \bullet$ A. Arora $\bullet$ S.K. Bradford

Savannah State University, Savannah, GA, USA

e-mail: aroraa@savannahstate.edu; aroraam@savannahstate.edu; bradfors@savannahstate.edu 